\title{
Escola básica: dois segmentos dissociados
}

\author{
Mariná Holzmann Ribas* \\ Rosilda Baron Martins* \\ Teresa Jussara Luporini*
}

\begin{abstract}
RESUMO
A Escola Básica constituiu-se num campo fértil de estudo e de investigações. Foi com essa perspectiva que se desenvolveu o projeto de pesquisa "Escola Básica: dois segmentos dissociados" que se originou com a constatação dos altos índices de evasão e repetência na $5^{\text {a }}$ série, gerados pelas dificuldades que os alunos de uma escola pública enfrentavam na passagem das séries iniciais para as finais do $1^{\circ}$ grau; tais dificuldades afloraram no desempenho dos alunos e nas queixas dos professores de $5^{\text {as }}$ séries. A análise foi estruturada em três eixos norteadores: a gestão interna da escola, a ação supervisora compartilhada e a disponibilidade dos professores da escola em desenvolver uma proposta que aprimora o fazer pedagógico dos envolvidos. Com isso, foi possível ver que quando existe o comprometimento com uma proposta pedagógica há a possibilidade de participação dos envolvidos na definição de conteúdos e de formas de ação. Além disso, quando efetivamente apoiada/acompanhada pela equipe técnico-administrativa, os resultados são consistentes e produtivos, gerando o sentimento de pertença e poder decisório em relação à unidade escolar.
\end{abstract}

Palavras chave: gestão interna da escola, ação supervisora compartilhada, disponibilidade dos professores

A integração dos segmentos da Escola Básica ${ }^{1}$ representa um ponto importante no ensino de $1^{\circ}$ grau, especialmente no que concerne aos assustadores

*Professoras da Universidade Estadual de Ponta Grossa - Doutoras em Educação.

${ }^{1}$ Nesse trabalho será mantida a expressão Escola Básica, denominação utilizada para referir ao Ensino Fundamental à época que a pesquisa foi desenvolvida (1992-1994).

Olhar de professor, Ponta Grossa, 1(1):57-73, out. 1998. 
índices de evasão e repetência. Apesar disso, é de conhecimento geral a dicotomia existente entre esses segmentos, pois as revistas especializadas em educação, os registros das Secretarias de Estado da Educação e os relatos dos professores têm divulgado amplamente este fato.

Vivendo concretamente as dificuldades dessa situação, o corpo técnico-administrativo e o corpo docente de uma escola de $1^{\circ}$ grau realizaram um projeto de desenvolvimento de recursos humanos, com o objetivo de favorecer a reflexão sobre as dificuldades apresentadas para a integração das diferenciadas disciplinas nos espaços distintos de sua concretização na sala de aula.

Tal projeto originou-se da percepção das tremendas dificuldades que os alunos enfrentavam na passagem da $4^{\mathrm{a}}$ para a $5^{\mathrm{a}}$ série, observadas pelo desempenho dos alunos e pelas queixas dos professores de $5^{\text {as }}$ séries.

O projeto, que pretendia também oportunizar a reflexão sobre as diferenciadas formas de tratamento dos variados conteúdos veiculados na escola de $1^{\circ}$ grau ( $1^{\mathrm{a}}$ a $8^{\mathrm{a}}$ série $)$, estruturou-se em três eixos para a sua execução:

- a força de gestão interna da escola;

- a ação supervisora compartilhada;

- a disponibilidade e o comprometimento dos professores da escola em desenvolver uma proposta que aprimorasse o fazer pedagógico pela troca de experiências domésticas próprias a cada ambiente escolar.

Considerando-se que toda escola, em maior ou menor grau de intensidade, segue o modelo de uma organização burocrática, é possível compreender que é nesse ambiente burocratizado que o corpo docente e o técnico da escola devem definir o seu papel: só assim a ação se torna dinâmica, através de formas de participação efetiva no ambiente escolar.

Acredita-se que havendo na escola uma ação conjunta, muitas lideranças emergem no grupo e assim se modificam as relações de poder na escola, possibilitando a efetivação da gestão interna, da supervisão compartilhada e do desenvolvimento pessoal.

Criado pela lei 5692/71 como um continuum, a escola de $1^{\circ}$ grau não atingiu seu objetivo, principalmente por apresentar-se fragmentada devido ao tratamento pedagógico e administrativo que recebe. $O$ fato vem sendo constante e veementemente denunciado pelos educadores nos mais variados eventos e na literatura especializada.

Entende-se que uma escola que sirva à maioria da população deva ser democrática, capaz de favorecer a compreensão de interesses diversos e de permitir a existência do conflito. Deve, ainda, apresentar contemporaneidade com o momento histórico, pela compreensão da realidade.

Partindo da crítica da escola pública atual, entende-se que a construção de uma escola realmente demo- 
crática passa pela melhoria das condições de acesso e da permanência do aluno, a quem se deve ofertar um ensino de boa qualidade.

Esse ensino de boa qualidade vincula-se à socialização do saber e à ação da escola pública na formação do cidadão. A escola deve existir para facilitar o domínio de instrumentos que propiciem ao aluno o acesso ao saber elaborado e ao conhecimento de como esse saber é produzido, viabilizando ações que democratizem a gestão interna da escola.

A democratização da escola passa, pois, pela decisão de organizar no próprio âmbito escolar práticas que assegurem um ensino competente.

A competência está indissoluvelmente ligada a um profundo conhecimento da escola e do processo educativo que se efetiva no dia-a-dia, processo este que se relaciona ao movimento social mais amplo.

$\mathrm{Na}$ literatura recente sobre educação, observa-se que as práticas cotidianas dos professores têm assumido duas direções distintas:

- algumas têm tentado caminhar em direção à mudança, servindo para que a escola se organize, ofereça condições favoráveis para a melhoria do ensino e colabore para o acesso e a permanência dos alunos (entre essas condições estão incluídas as propostas de aplicação de metodologias alternativas, de experiências que procuram favorecer a ligação entre o saber popular e o saber sistematizado);

- outras, caindo no pessimismo, têm exacerbado o peso da macro sobre a micro realidade, ficando na constatação de que pouco ou quase nada pode ser feito ou mudado (aqui se incluem as práticas pedagógicas legalistas que cumprem prazos e planejamentos e que produzem avaliações rigorosas e seletivas).

A realidade da escola apresenta um quadro que dificulta o desenvolvimento de propostas inovadoras em função do caráter altamente burocrático e centralizador do sistema escolar brasileiro.

Essa situação acaba se refletindo no ambiente escolar, obstaculizando as ações que encaminham para a autonomia da escola e contribuindo para o imobilismo dos profissionais que nela atuam. Isso colabora para que, na maioria das vezes, se espere que o sistema resolva pela escola o que é melhor para ela. E, também, para que medidas impositivas tomem aparência de normalidade, sem resistência por parte dos envolvidos.

Tudo isso leva à reflexão sobre o tipo de formação dos referidos profissionais e, ainda, sobre as oportunidades oferecidas pelo sistema de ensino a fim de que eles sejam estimulados a se posicionar diante de medidas autoritárias e a lutar por melhores condições de trabalho e de estudo.

Apesar do quadro apresentado, ainda existem escolas que reagem contra o imobilismo causado por situações adversas, criando espaços no já institucionalizado para refletir sobre as suas práticas, na tentativa de 
aperfeiçoá-las, e instituindo trabalhos diferenciados.

O desenvolvimento dessa forma de ação contribui para que a unidade escolar se destaque no sistema de ensino, mostrando a viabilidade das experiências que repudiam o caráter burocrático e legalista de educação formal, na busca de qualidade de ensino.

Sendo assim, as ações internas da escola podem potencializar ou minimizar as distorções do sistema educacional.

Considerando o exposto, depreende-se que a Escola Básica constituise num campo fértil como objeto de estudos e de investigações mais profundas, razões pelas quais decidiu-se optar por esta questão. Para a realização da pesquisa, foi definido como objetivo analisar se o desenvolvimento da proposta pedagógica da escola investigada possibilitou:

- a aproximação dos diferenciados campos de aplicação do ensino de $1^{\circ}$ grau;

- a reflexão sobre a metodologia específica das diversas áreas do conhecimento do ensino de $1^{\text {a }}$ a $8^{\mathrm{a}}$ série;

- a percepção da força da gestão interna na unidade escolar;

- um trabalho conjunto entre supervisores e professores no desenvolvimento das atividades pedagógicas da escola;

- a melhoria do desempenho do professor e, em conseqüência, um maior rendimento dos alunos;

- a percepção da importância da capacitação em serviço para o aperfeiçoamento do professor e as restrições que são feitas.

O problema percebido e definido para a investigação foi: a reflexão sobre a metodologia específica das diversas áreas do conhecimento e da metodologia do ensino de $1^{\text {a }}$ a $8^{\text {a }}$ série favoreceu a integração dos dois segmentos da Escola Básica?

O problema foi analisado com o intuito de conhecer os efeitos produzidos pelo trabalho desenvolvido na prática pedagógica desta escola e, também, a opinião dos professores sobre o processo e os efeitos percebidos na sua prática.

Foram consideradas todas as informações para uma coleta de dados a mais completa possível, contando com a colaboração de todos as pessoas englobadas na experiência, a fim de confirmar, rejeitar ou descobrir novos dados que permitissem a execução propriamente dita da pesquisa.

Para tanto, a proposta pedagógica da escola, os projetos, relatórios das atividades e dados coletados em questionários e entrevistas foram devidamente analisados.

\section{O pensado e o construído: um olhar sobre o cotidiano da escola}

Considerando o objetivo desta publicação e levando em conta que o trabalho realizado na escola ocorreu num longo espaço de tempo, envolvendo um grande número de ações, 
julgou-se pertinente destacar aquelas mais significativas. Nesta perspectiva, com a preocupação de não descaracterizar a experiência realizada, selecionaram-se as seguintes atividades:

- seminário de integração envolvendo professores, pais e alunos de $5^{\text {a }}$ série;

- reuniões mensais de estudo;

- horário especial de aulas para crianças de $4^{\mathrm{a}}$ série;

- reuniões quinzenais de planejamento.

O seminário de integração foi desenvolvido para discutir com os envolvidos (pais, alunos e professores) a estrutura e o funcionamento da escola, a proposta pedagógica para o ano letivo e, em especial, a sistemática de funcionamento da $5^{\text {a }}$ série.

Considera-se que essa atividade foi muito significativa, uma vez que se a escola pretende oferecer um ensino de qualidade à população, isso só se efetiva se houver a participação dos usuários.

Observa-se que as atividades selecionadas possuíam objetivos claros, fruto da reflexão por parte dos envolvidos, e eram voltados à construção do conhecimento, possibilitando o espaço de avaliação após a execução e o replanejamento em bases científicas. Ressalta-se o envolvimento do professor de $5^{\text {a }}$ série na definição da metodologia das atividades desenvolvidas em conjunto com os professores de $1^{\mathrm{a}}$ a $4^{\mathrm{a}}$ série, o que se constitui num aspecto essencial para a construção de metodologias alternativas.

Foram realizadas reuniões de estudo com os professores, para discutir suas necessidades e as da escola. Participaram dessas reuniões os professores, especialistas na área do conhecimento em estudo, supervisoras e direção. Os temas emergiram das discussões e foram trabalhados na perspectiva da construção coletiva do conhecimento, buscando-se sempre romper com as posturas cristalizadas. Procurou-se oferecer ao professor a oportunidade de construir o seu próprio conhecimento, repassando esta postura para a sala de aula na relação educador-educando.

Os registros indicam que foi muito enriquecedora a vivência de crescimento do grupo, na medida em que se quebrou a relação hierarquizada entre professores, supervisão e direção do estabelecimento, tradicionalmente visualizada como meio empregado pelo corpo técnico da escola para impor formas de ação ao corpo docente.

Pelo relato constata-se que é impossível sonhar com a melhoria do ensino sem promover a melhoria da formação dos professores. É preciso refletir sobre essa formação, a qual compreende a atualização, o aperfeiçoamento e a avaliação dos professores, a fim de poder contribuir para sua modificação e melhoria.

Para que a escola cumpra as suas funções, dando o devido atendimento à classe majoritária do país, a boa 
formação dos profissionais que nela atuam é fundamental. Faz-se necessário, pois, que os professores se submetam a um processo de reeducação por meio da capacitação em serviço, redimensionando conteúdo e metodologia, teoria e prática e, dessa forma, atuando mais efetivamente junto à clientela da escola pública. É pelo processo de troca de saberes que se chega a uma nova atitude: a de aceitação de prioridades definidas a partir das necessidades concretas da escola. Esse efetivo processo de troca leva a um aprendizado progressivo de enfrentamento das diferenciadas situações que se apresentam no cotidiano escolar.

No que se refere à quebra da relação hierarquizada entre os profissionais envolvidos, é pertinente observar que a ação supervisora compartilhada atesta a possibilidade de oportunizar o desenvolvimento de lideranças nas diferentes atividades da vida escolar. As lideranças emergem no grupo e assim se modificam as relações de poder no ambiente escolar, pois o grupo toma consciência de suas necessidades e limites, e age a partir da consciência coletiva.

O horário especial de aulas para as $4^{\text {as }}$ séries simulou o funcionamento de uma $5^{\text {a }}$ série regular, para que os alunos fossem se acostumando com a sistemática da série, isto é, com a troca de professores a cada aula de 50 ou 100 minutos. Os pais foram avisados sobre o desenvolvimento desse horário, para que pudessem acompanhar a mudança e tecer considerações a respeito.

A receptividade de alunos e professores de $4^{\mathrm{a}}$ série foi excelente, o que facilitou sobremaneira o trabalho dos professores de $5^{\text {a }}$ série. Também foi possível perceber que os professores avançaram na compreensão das dificuldades existentes em cada segmento, o que os levou a construir uma nova prática, um novo conhecimento sobre o currículo e a aplicação deste no ensino de $1^{\mathrm{a}}$ a $8^{\mathrm{a}}$ série. Essa postura permitiu que fossem adotadas formas de trabalho mais democráticas, favorecendo uma efetiva participação e melhor rendimento dos alunos.

Os dados coletados indicam que as relações entre os profissionais envolvidos no trabalho pautavam-se pela confiança e pela consciência de um trabalho coletivo. São comuns as críticas dos professores de $5^{\mathrm{a}}$ a $8^{\mathrm{a}}$ série ao trabalho que desenvolvem os professores de $1^{\text {a }}$ a $4^{\text {a }}$ série, geralmente considerado inadequado para que os alunos acompanhem o segundo segmento de $1^{\circ}$ grau. Isso dá uma idéia do avanço que o projeto oportunizou: tanto o professor de $4^{\mathrm{a}}$ série recebeu o colega de $5^{\text {a }}$ série e permitiu que ele interferisse em seu cotidiano, para que conhecesse os seus procedimentos pedagógicos, quanto estes socializaram os conhecimentos pertinentes à área em que atuam.

Ressalte-se ainda que esse momento de execução da atividade resultou de estudos e de planejamento 
coletivo, que facilitaram a constituição de um espaço de diálogo em que a crítica se faz necessária para o aperfeiçoamento do trabalho. Deve-se destacar ainda que, provavelmente, este foi um momento delicado no desenvolvimento do projeto porque cada profissional, ao se expor às críticas, abriu espaço para reflexão sobre a sua própria prática.

Considerados os objetivos do projeto, é possível visualizar a atividade de troca entre os professores como muito significante para a consecução do que se pretendeu atingir. E isso sem deixar de levar em conta tudo o que realizou, que funcionou como alicerce para que fosse alcançado um novo patamar.

As reuniões quinzenais com professores de $1^{\text {a }}$ a $8^{\text {a }}$ série, que contaram com a participação das supervisoras, tinham como finalidade o planejamento do trabalho a ser desenvolvido e, também, a avaliação do trabalho realizado na quinzena anterior.

Esse trabalho deve ter contribuído, e muito, para a construção de propostas metodológicas alternativas, pois, provavelmente, permitiu o encontro de saberes e experiências profissionais muito diversificadas.

A avaliação de todas as atividades desenvolvidas no decorrer do ano letivo ocorreu de forma contínua com base na apreciação dos professores e nos pontos positivos e negativos levantados. Estes aspectos consubstanciaram o apoio para o planejamen- to das atividades subseqüentes. permitindo a correção dos desvios e o aperfeiçoamento das propostas consideradas eficientes.

Para a avaliação das atividades, realizaram-se encontros com a participação de todos os envolvidos e foram apontados os pontos válidos para as reflexões acerca do trabalho, da integração dos dois segmentos, do melhor relacionamento entre os professores de $1^{\text {a }}$ a $4^{\mathrm{a}}$ série e, o mais importante da percepção de que a escola possui um projeto coletivo, passível de execução, que colabora para a melhoria do ensino oferecido.

Esta é a questão fundamental da formação em serviço, porque os avanços só podem ocorrer se há a clareza quanto aos propósitos: "quando o professor conscientiza-se da realidade existente na profissão, no próprio desempenho da função, é quando, na realidade, se inicia a verdadeira formação ou reeducação. A formação do educador, portanto, não se dá de fora para dentro" (RIBAS, 1989, p. 68).

Além da avaliação contínua, no final do ano foi realizada uma avaliação global do trabalho. Segundo os professores, os resultados foram considerados excelentes, tanto no que se refere ao seu próprio desempenho quanto ao desempenho dos alunos.

Pode-se inferir que embora alguns professores percebam os resultados do ponto de vista do corpo docente e outros os percebam em função do desempenho dos alunos, a questão primordial é a que se refere à refle- 
xão sobre a própria prática pedagógica. Isto porque se os alunos avançam na direção de comportamentos reflexivos, criativos e independentes, estes refletem o crescimento do professor no desempenho de sua função.

É interessante notar que a influência da formação em serviço ocorre de modo diferenciado em cada um dos profissionais que atinge. Na questão que ora se analisa, percebe-se, por um lado, que enquanto alguns professores visualizam os resultados pela ótica da sala de aula, outros apresentam uma visão mais abrangente, dirigida ao contexto global da experiência. Isso indica que tanto uns quanto outros demonstram que a capacitação em serviço deve ser realizada de tal forma que os próprios professores percebam a situação em que se encontram, o papel da escola, o que ela está fazendo, e o que pode ser feito. São os professores que devem sentir a necessidade de mudar, de buscar novas formas de atuação, de propor situações diferentes. Só assim serão profissionais atuantes, criativos e inventores de idéias.

É verdade que os efeitos provocados pela capacitação em serviço são consideráveis, principalmente no tocante ao relacionamento professor/ aluno, professor/professor, professor/ equipe (técnico-pedagógica e administrativa). Embora sejam fatores importantes para o processo de aprendizagem, é preciso refletir que, sozinhos, não garantem que o aluno aprenda, desenvolva um espírito crítico, seja estimulado a desenvolver certas capacidades com as condições existentes na escola e no meio e seja capaz de encontrar seu lugar no mundo em que vive. É preciso uma mudança mais profunda na prática pedagógica do professor, para que interfira mais significativamente no cotidiano escolar e se reflita na comunidade. É preciso dar continuidade a propostas que consolidem as ações pedagógicas.

Também influem neste processo a formação profisssional, o ambiente organizacional das unidades escolares, as práticas centralizadoras dos órgãos da administração do ensino e a própria sociedade brasileira, fortemente conservadora.

As práticas centralizadoras fortalecem o poder organizacional ou formal, que é distribuído entre os elementos que constituem uma estrutura que, por sua vez, limita o poder pessoal. Já o poder organizacional cerceia a renovação, porque dirige a capacidade de trabalho de seus recursos humanos para procedimentos padronizados, mecanicistas e controladores, restringindo a iniciativa pessoal.

Esta é a razão de a gestão interna se constituir num exercício cotidiano de conquista da voz, do espaço profissional, da tomada de decisões num processo coletivo e democrático, administrando o poder para dar abertura à maior utilização possível das potencialidades pessoais. Por maiores dificuldades que essa gestão apresente aos envolvidos, ela traz alguns 
avanços, pois os professores passam a assumir posições, a argumentar e a criticar os colegas que não o fazem.

Esse fato remete à discussão sobre o envolvimento dos profissionais em seu ambiente de trabalho, envolvimento que parece ser tanto mais abrangente quanto maior for a clareza dos propósitos a atingir, contribuindo para que as decisões coletivas possam contornar medidas impostas pelos órgãos da administração do ensino e/ou desencadear a construção de um projeto coletivo na escola.

É válido ressaltar que, num grupo numeroso e heterogêneo, o nível de participação é desigual. Isso ocorre por vários fatores, entre os quais se pode incluir a constante mudança do quadro de professores (que não acompanharam o desenvolvimento do processo desde o seu início e nem podem acompanhá-lo por muito tempo, pois não criam raízes na escola). Isso contribui para o descompromisso. Deve ser considerado também que mesmo entre professores efetivos há os que não se comprometem, por se considerarem voto vencido nas decisões ou por serem acomodados ou inibidos (não expressando assim a sua opinião e não se posicionando). Isso faz com que eles não acatem os posicionamentos do grupo. Percebese que tais professores não demonstram suficiente maturidade para inserir-se no coletivo, posicionando-se muito mais pessoal do que profissionalmente, em decorrência de uma falta de visão abrangente da realidade es- colar que está próxima e, especialmente, da realidade educacional muito mais ampla e abstrata.

Tais profissionais obstaculizam as perspectivas de avanço da unidade escolar, reproduzindo, muitas vezes, o sistema social vigente, em que as pessoas não são capazes de se autodeterminarem nem de criarem espaços próprios e criativos. Segundo Pedro Demo, essas pessoas constituem "massa de manobra, nas mãos de uma oligarquia tão restrita quanto tacanha" (DEMO, 1988).

De modo geral, perceberam-se as possibilidades da força da gestão interna, a qual se caracterizou no desenvolvimento da proposta como um todo, apesar dos obstáculos a serem superados, devido à heterogeneidade do grupo de profissionais atingido pela experiência. Foi observado que os professores vislumbraram a possibilidade de participação, embora nem sempre a tivessem utilizado. Provavelmente, isso ocorreu devido à falta de hábito e até de habilidade para a tomada de decisões coletivas.

A prática da supervisão compartilhada possibilitou, segundo os depoentes, a melhoria do desempenho docente e discente. Além disso, permitiu que os professores construíssem uma nova imagem da função supervisora, afastando-se de atitudes de subordinação/acomodação para caminhar em direção de uma prática pedagógica autônoma, formando pontos de vista, discutindo, argumentando e, até mesmo, criticando os cole- 
gas que não se sensibilizaram com o movimento de reorganização do espaço escolar.

Para tanto, foi imprescindível a prática da ação supervisora compartilhada: aquela "desenvolvida conjuntamente para supervisores e professores, em termos de igualdade, coordenarem e desenvolverem as atividades pedagógicas da escola" (FALCÃo FILHO, 1987, p. 5).

O maior ganho ficou por conta da tomada de decisões conjuntas de profissionais dos dois segmentos da Escola Básica, que planejaram, executaram, acompanharam e avaliaram as ações educativas, interferindo na construção do currículo entendido como o "conjunto das atividades nucleares da escola" (PARANÁ, 1990, p. 16).

Um aspecto a ressaltar é a significação da troca de saberes entre os profissionais envolvidos, com todas as dificuldades que isso acarretou. $\mathrm{O}$ professor teve oportunidade de sentir-se detentor de um saber específico, ao mesmo tempo que reconheceu no outro, seu par, uma competência singular. Houve necessidade de criação de relações dialogais, de divisão do poder, de quebra de hierarquização de cargos e posicionamentos, oportunizando um apoio mútuo entre os profissionais envolvidos.

Outro aspecto a considerar é que, embora em minoria, alguns profissionais não foram atingidos pela proposta, não a incorporando, não acreditando na possibilidade e não se en- tusiasmando. Esses profissionais não melhoraram a sua competência política e técnica, apenas reproduzindo as descobertas efetuadas por seus colegas.

Uma outra questão a ser considerada é que, embora o processo democratizante na unidade escolar tenha se originado no projeto pedagógico, fatalmente ele permeou outras ações e decisões ocorridas em função do corpo docente como um todo. Por outro lado, as influências centralizadas e autoritárias do sistema educacional também se fizeram presentes em determinados momentos, pois, certamente, não há concepção teórica que se apresente em sua pureza. Daí a necessidade do equilíbrio e da sensibilidade do grupo para perceber estas nuances, reavaliar os posicionamentos e redefinir as ações em direção das práticas democratizantes.

Em todo esse contexto, há mais um fator positivo que merece ser ressaltado: o empenho da equipe técnico-pedagógica e administrativa no aperfeiçoamento de suas ações e no convencimento daqueles profissionais que não se envolvem, que resistem às inovações, que são pessimistas. As resistências de tais profissionais sempre são consideradas quando se planejam atividades e isto acaba colaborando para que se estabeleçam estratégias a fim de ultrapassar tais barreiras, o que de certa forma propicia o avanço das práticas desenvolvidas na unidade escolar e, conseqüentemen- 
te, o crescimento dos envolvidos.

Percebeu-se também que, pela vivência da proposta, muitos professores passaram a ter maior clareza de suas limitações e a sentir a necessidade de buscar maiores esclarecimentos, inclusive no que respeita às sugestões quanto à sistemática e à freqüência das ações executadas.

Uma proposta deste tipo constitui, pois, uma oportunidade de fazer aflorar uma nova postura, a busca de educação permanente, naqueles professores que, às vezes, acham que está tudo bem e que sabem tudo quando a realidade é outra.

A busca de educação permanente implica a consciência de que, dada a evolução das ciências, nunca se sabe o suficiente. Para isso, é preciso reconhecer que a atualização depende de constantes estudos e do convívio com pessoas e experiências diferentes, que ampliam o aprendizado e possibilitam o mútuo crescimento.

A criação de grupos de reflexão e estudo na própria escola é o caminho para esse crescimento e para as modificações necessárias, partindo das próprias condições e possibilidades do professor e da escola.

Para tanto, é preciso um trabalho continuado, que se constitua num real processo de estudo, de reflexão, de crítica e de revisão daquilo que se pensa e daquilo que se faz. Trabalho, na verdade, muito mais indicado para o desenvolvimento pessoal dos professores e para a melhoria da prática pedagógica.
Confrontando, nesta pesquisa, as opiniões, a prática e as sugestões sobre o treinamento em serviço, também identificado como capacitação e educação em serviço, percebe-se que pode ocorrer resistência do professor a inovações. Entretanto, quando existe o comprometimento com uma proposta pedagógica, há a possibilidade de participação na definição de conteúdos e formas de ação a adotar. Mais ainda, quando a ação educativa é efetivamente apoiada pelos envolvidos e acompanhada pela equipe técnicoadministrativa, como é o caso do trabalho examinado nesta pesquisa, os resultados são consistentes e produtivos. Isto ocorre pelo fato de o processo partir das necessidades do professor e da escola, criando um ambiente mais natural em que são discutidos os elementos essenciais a serem trabalhados.

É preciso sempre ter em mente que os resultados obtidos foram alcançados em função da prática da gestão interna e da supervisão compartilhada, uma vez que ocorreram a divisão do poder, a troca de saberes e a quebra da hierarquização de cargos e posicionamentos.

Para atingir uma melhor competência profissional, é importantíssimo que a escola se relacione com outras instâncias educacionais - Núcleo Regional da Educação (NRE), universidade, outras escolas... - para estudar, pensar e debater questões amplas e restritas que a afligem. Isto permite uma abertura da escola ao mesmo 
tempo que colabora para o avanço do estudo e da discussão dos temas mais gerais que subsidiam as reflexões sobre a educação brasileira e, em especial, sobre a escola pública.

No caso analisado, esta perspectiva se efetivou devido ao envolvimento dos profissionais da equipe técnico-pedagógica e administrativa com a universidade e devido à divulgação, por iniciativa da própria escola, da experiência em evento educacional.

Considerando os depoimentos e a análise dos dados, é importante ressaltar que seria necessária a continuidade da proposta na escola, para consolidar os avanços e persistir na produção de resultados cada vez mais significativos.

Isto se dá em função de, em educação, os avanços serem lentos, exigindo persistência dos profissionais na execução de propostas que apresentem bons resultados. Um aspecto que pode dificultar a continuidade de trabalhos desta natureza é a rotatividade de professores, que atrapalha o prosseguindo na busca do aprimoramento do trabalho desenvolvido na escola.

O repensar na teoria: encaminhamento de uma nova prática

A questão crucial, em educação, reiteradamente discutida, refere-se à qualidade do ensino oferecido pela escola pública. Entendendo que essa qualidade está intimamente ligada ao desenvolvimento de projetos específicos, peculiares, particulares à realidade vivenciada, foi que se desenvolveu este trabalho que tem a certeza de que o centro da questão - a qualidade do ensino - tem a ver com o fenômeno participativo.

"Participação é o processo histórico de conquista da auto-determinação, da capacidade de definir o horizonte de sua caminhada" (GANDIN, apud CRUZ, 1993, p. 25). Segundo o autor, existem três níveis de participação: colaboração, delegação de poder e construção conjunta.

O primeiro indica participação em seu nível mais rudimentar, em que as pessoas são intimadas a colaborar num projeto, sem questionar a sua criação, a fim de que tudo ocorra dentro do estabelecido pelos dirigentes.

Delegação de poder indica um nível mais avançado de participação, onde os dirigentes dividem parcialmente o seu poder com outras pessoas, embora se mantenha a estrutura básica de poder.

O terceiro nível de participação é o da construção conjunta. Neste estágio, ocorre a ruptura entre o planejador e o executor: as diretrizes e as finalidades da proposta educativa, assim como as fases e os modos de sua execução, são conjuntamente estabelecidos por todos os envolvidos na unidade escolar.

$\mathrm{Na}$ experiência, o objeto de análise deste projeto, percebe-se nuances da passagem da delegação de poder à construção conjunta, uma vez que a 
proposta foi apresentada ao corpo docente, tendo a discussão resultado da decisão coletiva de desenvolvê-la.

No desenvolvimento da proposta, foram percebidos avanços em direção da participação como construção conjunta e, também, recuos no sentido da participação como delegação de poder. Esses avanços e recuos dependem do profissional envolvido na mesma, da situação e do momento. E é justamente esta heterogeneidade de pessoas e de situações que confere riquezas à experiência, considerando-se que "participação não é ausência, superação, eliminação de poder, mas outra forma de poder" (DEMO, 1987, p. 69).

Pesquisas recentes realizadas nos mais diversos tipos de organização indicam que o homem, quando participa da definição dos destinos de sua organização, coloca à disposição da mesma poderosas forças que o fazem contribuir mais e melhor para o alcance de determinados objetivos - seus e da instituição à qual pertence. Todas as suas qualidades pessoais e profissionais são colocadas, pois, a serviço de objetivos bem definidos.

Isto comprova que, conforme FALCÃo FILHO (1986, p. 4), "cada professor com o seu referencial próprio, fruto de uma interação própria, percebe cada aspecto do ambiente da escola de uma forma muito particular, geradora de reações ou comportamento específicos".

Isso revela o valor das discussões coletivas, dos grupos de estudos e do planejamento conjunto, em que cada profissional pode dar a sua contribuição, explicitando a sua visão de realidade e expressando o seu poder pessoal, o que normalmente dirige-se para resultados, fazendo crescer a criatividade, a sensibilidade, a iniciativa própria, a inovação e a flexibilidade. Esses fatores, portanto, contribuirão para que a escola acompanhe as muitas e rápidas mudanças ocorridas na sociedade.

Além disso, poderão favorecer uma maior aproximação do professor com o objeto de seu trabalho, gerando sentimento de pertinência e co-responsabilidade. Tais aspectos são facilitadores para que ocorra a gestão interna que, segundo SONIA PENIN, é uma proposta com o objetivo de indicar ações "que viabilizem a consecução dos princípios básicos de democratização, ou seja, o acesso e permanência do aluno à escola e a melhoria de qualidade do ensino para toda a população" (1989, p. 81).

A força de gestão interna é limitada por comportamentos competitivos, que a cultura individualista condiciona. Não é algo que surge naturalmente, deve ser conquistada pouco a pouco, com convicção e persistência.

Cabe discutir a questão do poder na escola, uma vez que, no seu cotidiano, atua um conjunto de forças dinâmicas, em contínua interação, expressando-se em diferentes e conflitantes direções. É aí que se origina um foco constante de tensão que, em sua 
essência, nada mais é do que uma luta política pelo poder, pela preponderância de determinados pontos de vista no interior da escola.

A percepção do poder no cotidiano escolar é básica para que o profissional visualize de forma ampla o contexto onde se insere, o que facilita o seu envolvimento no cotidiano, contribuindo para o aperfeiçoamento das questões pedagógicas. A sua maior participação faz com que o poder nessa área se divida, o que aumenta a sua autonomia e a sua consciência quanto ao processo desenvolvido. A partir deste ponto, esse profissional estará apto a colaborar para mudanças institucionais, uma vez que "aumenta, também, a pertença do professor ao projeto pedagógico" (CRUZ, 1993, p. 26).

É pertinente lembrar que as decisões institucionais são legitimadas pelas práticas cotidianas. Só quando o grupo se encontra apto para colaborar nas mudanças institucionais (na micro-realidade), ele é capaz de se posicionar diante de uma realidade adversa, tendo consciência da possibilidade da "desobediência civil", a qual constitui também forma de participação na macro-realidade.

Essa consciência política fortalece a proposta pedagógica da escola, pois, conscientes e comprometidos com a realidade onde se inserem, os professores podem enfrentar com competência os desafios que se apresentam no cotidiano da escola pública. "A escola pública - é bom repetir
- é a única verdadeiramente aberta, democrática e que pode realizar concretamente os ideais de uma sociedade mais justa e mais democrática. Importa valorizá-la, valorizando suas instalações, seu professor, lutando pela ampliação da permanência diária do aluno na escola e pelo aumento do número de dias letivos. Fazer o contrário, como as vezes o espírito corporativo bitolado nos mostra, é atitude política retrógrada que só favorece o privatismo e os interesses comerciais na educação" (GARCIA, 1989, p. 10).

A qualidade do ensino que se desenvolve nas unidades escolares do sistema público está diretamente ligada à competência dos profissionais que nela atuam e à sua resistência à ideologia que permeia o sistema educacional. Uma das formas de resistência, em busca da qualidade, é a execução de pequenos projetos nas próprias escolas, oriundos de suas necessidades específicas. Tais projetos resultam numa maior eficácia por estarem mais próximos da realidade cotidiana da escola. Isto porque, como diz Gadotti, "só as escolas conhecem de perto a comunidade e seus projetos, [podendo assim] dar respostas concretas a problemas concretos de cada uma delas" (GADOTTI, 1992. p. 69). Entretanto, esta perspectiva não exclui a consciência de que cada unidade escolar está inclusa no sistema educacional com o qual se relaciona diuturnamente e de que não deve fechar-se em si mesma por se conside- 
rar auto-suficiente, sob pena de produzir a autofagia. Inclusive, o resultado de suas experiências deve ser encaminhado aos órgãos centrais da administração do ensino para serem socializados. Isto porque, além de a escola divulgar os seus avanços, pode também beneficiar-se das conquistas de outras unidades escolares, estabelecendo um intercâmbio que a fortalecerá cada vez mais.

Nunca é demais ressaltar que para o desenvolvimento de projetos na escola, há necessidade de se contar com um corpo docente que se comprometa com uma educação com perspectivas de transformação e que apresente valores como a participação, o senso crítico, a solidariedade, a consciência política. E quanto mais tais valores estiverem presentes no cotidiano, maiores possibilidades se apresentarão para que a escola comece a instruir as suas próprias normas. Desse modo, a escola passa a possuir maior especificidade em sua caminhada, na construção de sua história. Mas é preciso ter a clareza de que isto só é possível em função dos avanços e recuos produzidos durante a trajetória da unidade escolar e de que estes avanços e recuos são igualmente necessários por se constituírem em fatores de crescimento de uma comunidade.

Daí a necessidade de que os profissionais da educação sejam otimistas, militantes e obstinados.

Concretizar a ação política da escola é ampliar o acesso e socializar o conhecimento sistematizado, pontos fundamentais para a organização da escola e para a democratização de sua gestão interna, "com compromisso de decidir, no âmbito da própria escola, sobre a organização e as práticas que melhor assegurem aqueles princípios que a gestão interna se legitima e, nesse sentido, deve e precisa ser exercida" (PENIN, 1989, p. 81).

As práticas pedagógicas devem ser organizadas no sentido de ensinar bem e efetivar o melhor domínio possível das matérias do currículo, valorizando, especialmente, as formas de expressão e comunicação. Tais formas devem considerar a clientela que freqüenta a escola pública, clientela esta que apresenta características fortemente influenciadas por aspectos econômicos e socioculturais.

SILVA (1989, p. 67) afirma que "somente através da adequação pedagógico-didático às condições de vida material, às características psicológicas e socioculturais dos alunos, será possível atender à exigência de um currículo comum e de um ensino diversificado e de qualidade para a escola pública de hoje".

Não é demais repetir que a construção desta escola de boa qualidade passa pelo enfrentamento do desafio da mudança interna: "é preciso acreditar ainda na escola e tentar mudá-la por dentro e de dentro para fora" (MENDES, 1985, p. 17).

Considerando que toda proposta de melhoria da escola pública deve conter intervenções de caráter pedagógico, entende-se que o ensino é um 
exercício de gestão: os profissionais de ensino planejam, executam e avaliam seu desempenho em função da aprendizagem dos alunos, ou seja, administram tempo, espaço e materiais de apoio, facilitam a aprendizagem dos alunos, agindo como mediadores entre o conhecimento sistematizado e as suas experiências informais.

Enquanto construção coletiva, a escola assume-se como locus de construção do conhecimento de aperfeiçoamento dos profissionais de ensino, devendo possibilitar o encontro sistemático de seus membros para discussões e reflexão sobre os problemas de seu cotidiano. Porém, o processo de participação exige do grupo flexibilidade, continuidade e persistência para que ocorra um amplo envolvimento e uma visão global da educação, não se limitando a este ou àquele aspecto, mas à escola enquanto espaço a ser direcionado em termos de sua reorganização.

\section{REFERÊNCIAS BIBLIOGRÁFICAS}

1 CANDAU, V. M. Pensando a formação do educador/supervisor. Tecnologia Educacional, Rio de Janeiro, n.49, p.22-6, nov./dez., 1982.

2 CRUZ, Carlos H. C. Educação libertadora - como projeto político social. Revista da Educação. Brasília, v.22, n.87, p.15-33, abr./jun, 1993.
3 DEMO. Participação é conquista. São Paulo: Cortez, 1988.

4 FALCÃO FILHO, José L. As relações entre o supervisor pedagógico e os professores. AMAE Educando. Belo Horizonte, n.20, p.31-6, ago./ 1987.

5 __ Supervisão uma análise crítica das críticas. AMAE Educando. Belo Horizonte, p.30-7, abr./1990.

6 _. Uma visão compartilhada. AMAE Educando. Belo Horizonte, p.4-12, maio, 1986.

7 GADOTTI, Moacir. Escola cidadã. São Paulo: Cortez, 1992.

8 GANDIN, Danilo. Planejamento educacional. Porto Alegre: UFRGS, 1991.

9 GARCIA, Walter E. Decisões políticas para uma educação democrática. Tecnologia Educacional. v.17/18, n.85/ 86, p.7-10, nov./88, fev./89.

10 KRAMER, Sônia. Melhoria da qualidade do ensino: o desafio da formação de professores em serviço. Revista Brasileira de Estudos Pedagógicos. Brasília, v.70, n.165, p.189-207, maio/ago. 1989.

11 LUPORINI, T. J. Pesquisando e compreendendo história: uma experiência com alunos da $8^{\text {a }}$ série. Dissertação (Mestrado) Pontíficia Universidade Católica de São Paulo, 1989. 
12 MACIAN, Leda M. Treinamento e desenvolvimento de recursos humanos. São Paulo: EPU, 1987.

13 MARQUES, J. C. Administração participativa: poder, conflito e mudança na escola. Porto Alegre: Sagra, 1987.

14 MARQUES, Mário Osório. Projeto pedagógico: a marca da escola. Contexto \& Educação. v.5, n.18, p.11-7, abr./jun. 1990.

15 MEDIANO, Zélia D. A formação em serviço do professor a partir da pesquisa e da prática. Tecnologia Educacional, v.21, n.105/106, p.31-7, maio/ jun. 1993.

16 MENDES, Rosa E. de. A. Supervisão pedagógica: do modelo burocrático ao modelo participativo. Revista da Educação, v.14, n.57, p.7-17, jul./set. 1985.

17 PENIN, Sonia T. de S. Política educacional: o revigoramento a partir das práticas cotidianas. Cadernos de Pesquisa. São Paulo, n.69. p. 80-5, maio, 1989.

18 _ Cotidiano e escola: a obra em construção. São Paulo: Cortez, 1987.

19 RIBAS, Mariná H. Treinamento de professores: sua validade e seus efeitos na prática docente. Uma análise da questão no Estado do Paraná. Dissertação (Mestrado). Pontíficia
Universidade Católica de São Paulo, 1989.

20 SILVA, Tereza R. N. da. Contextualizando o currículo escolar. Idéias, São Paulo, FDE, n.1, p.65-72, 1989.

21 SCHMIDT, Leide Mara. A instituição escola numa perspectiva de renovação. Dissertação (Mestrado) Pontíficia Universidade Católica de São Paulo, 1989. 